\title{
Fatigue and damage of porcine pars interarticularis during asymmetric loading
}

\author{
Colin Bright \\ Technological University Dublin, colin.bright@tudublin.ie \\ Stephen Tiernan \\ Technological University Dublin, stephen.tiernan@tudublin.ie \\ Fiona McEvoy \\ Technological University Dublin, fiona.mcevoy@tudublin.ie
}

See next page for additional authors

Follow this and additional works at: https://arrow.tudublin.ie/ittengart

Part of the Engineering Commons, and the Medicine and Health Sciences Commons

\section{Recommended Citation}

Colin Bright, Stephen Tiernan, Fiona McEvoy, Pat Kiely, Fatigue and damage of porcine pars interarticularis during asymmetric loading, Journal of the Mechanical Behavior of Biomedical Materials, Volume 78, 2018, Pages 505-514, ISSN 1751-6161, DOI: 10.1016/j.jmbbm.2017.12.008.

This Article is brought to you for free and open access by the School of Engineering at ARROW@TU Dublin. It has been accepted for inclusion in Articles by an authorized administrator of ARROW@TU Dublin. For more information, please contact arrow.admin@tudublin.ie, aisling.coyne@tudublin.ie,gerard.connolly@tudublin.ie. Funder: Irish Research Council

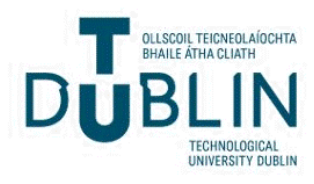


Authors

Colin Bright, Stephen Tiernan, Fiona McEvoy, and Pat Kiely

This article is available at ARROW@TU Dublin: https://arrow.tudublin.ie/ittengart/7 


\title{
Fatigue and damage of porcine pars interarticularis during asymmetric loading
}

\author{
Colin Bright $^{\mathrm{a}, *}$, Stephen Tiernan ${ }^{\mathrm{a}}$, Fiona McEvoy ${ }^{\mathrm{a}}$, Pat Kiely ${ }^{\mathrm{b}}$ \\ a Institute of Technology, Tallaght, Tallaght, Dublin 24, Ireland \\ b Our Lady's Children's Hospital, Crumlin, Dublin, Ireland
}

\section{A R T I C L E I N F O}

Keywords:
Spine
Bone
Spondylolysis
Facet
Pars interarticularis
Strain
Rosette gauge
Hysteresis
Fracture
Damage

\begin{abstract}
A B S T R A C T
If the articular facets of the vertebra grow in an asymmetric manner, the developed bone geometry causes an asymmetry of loading. When the loading environment is altered by way of increased activity, the likelihood of acquiring a stress fracture may be increased. The combination of geometric asymmetry and increased activity is hypothesised to be the precursor to the stress fracture under investigation in this study, spondylolysis. This vertebral defect is an acquired fracture with $7 \%$ prevalence in the paediatric population. This value increases to $21 \%$ among athletes who participate in hyperextension sports. Tests were carried out on porcine lumbar vertebrae, on which the effect of facet angle asymmetry was simulated by offsetting the load laterally by $7 \mathrm{~mm}$ from the mid-point. Strain in the vertebral laminae was recorded using six 3-element stacked rosette strain gauges placed bilaterally. Specimens were loaded cyclically at a rate of $2 \mathrm{~Hz}$. Fatigue cycles; strain, creep, secant modulus and hysteresis were measured.

The principal conclusions of this paper are that differences in facet angle lead to an asymmetry of loading in the facet joints; this in turn leads to an initial increase in strain on the side with the more coronally orientated facet. The strain amplitude, which is the driving force for crack propagation, is greater on this side at all times up to fracture, the significance of this can be observed in the increased steady state creep rate $(p=0.036)$ and the increase in yielding and toughening mechanisms taking place, quantified by the force-displacement hysteresis ( $\mathrm{p}$ $=0.026)$.
\end{abstract}

\section{Introduction}

Spondylolysis is a stress fracture of the pars interarticularis, part of the posterior portions of the vertebra. A number of authors have proposed facet joint asymmetry as a precursor for this stress fracture (Rankine and Dickson, 2010; Masharawi et al., 2007; Crawford et al., 2015), however to date none have examined this using a mechanical methodology. When bones grow in an asymmetric manner, the underlying structure adapts to this new loading environment over time (Frost, 2004). During normal loading such as that experienced with every-day activities the asymmetric structure is sufficient. However, when the loading environment is altered by way of increased activity the asymmetric structure alters the apportionment of load and increases the incidence of stress fractures of the pars interarticularis (Rankine and Dickson, 2010; Masharawi et al., 2007). This vertebral defect is an acquired fracture with a $7 \%$ prevalence in the paediatric $(<18$ years old) population (Hensinger, 1989), however, this number increases in the athletically active population with a prevalence of up to $11 \%$ of female gymnasts (Jackson, 1976), 10.5\% of Swedish athletes (Swärd et al., 1989) and $10.7 \%$ of Canadian gymnasts ( > 10 years old) (Toueg et al., 2010). It can occur unilaterally which ordinarily leads to healing, or bilaterally, which in chronic cases can lead to the establishment of non-union and grade 1 or 2 spondylolisthesis (anterior displacement of the vertebral body) (Beutler et al., 2003; Rankine and Dickson, 2010). The fracture occurs at the lowest lumbar level in $90 \%$ of cases and many patients with spondylolysis will develop significant lumbar complications in later life (Crawford et al., 2015).

When this stress fracture occurs it has been shown to originate in the caudal (lower) vertebra of the pair of vertebrae in question, and on the ventral aspect (facing the abdomen) of the pars interarticularis (Terai et al., 2009). The pars interarticularis fits Currey's (Currey, 1984) description of a "sandwich" bone, that is, a pair of cortices comprised of cortical bone bearing the bending load with trabecular filling maintaining the space between them, thus keeping the second moment of area large. The backward bending force created by extension of the spine is transmitted to the pars interarticularis via the facet joints. The force inducing this bending is applied perpendicular to the principal axis of the pars, on a plane which is $30^{\circ}$ from the mid-plane of the

\footnotetext{
* Correspondence to: Bioengineering Technology Centre, Institute of Technology Tallaght, Tallaght, Dublin 24, Ireland.

E-mail address: Colin.Bright@ittdublin.ie (C. Bright).
} 

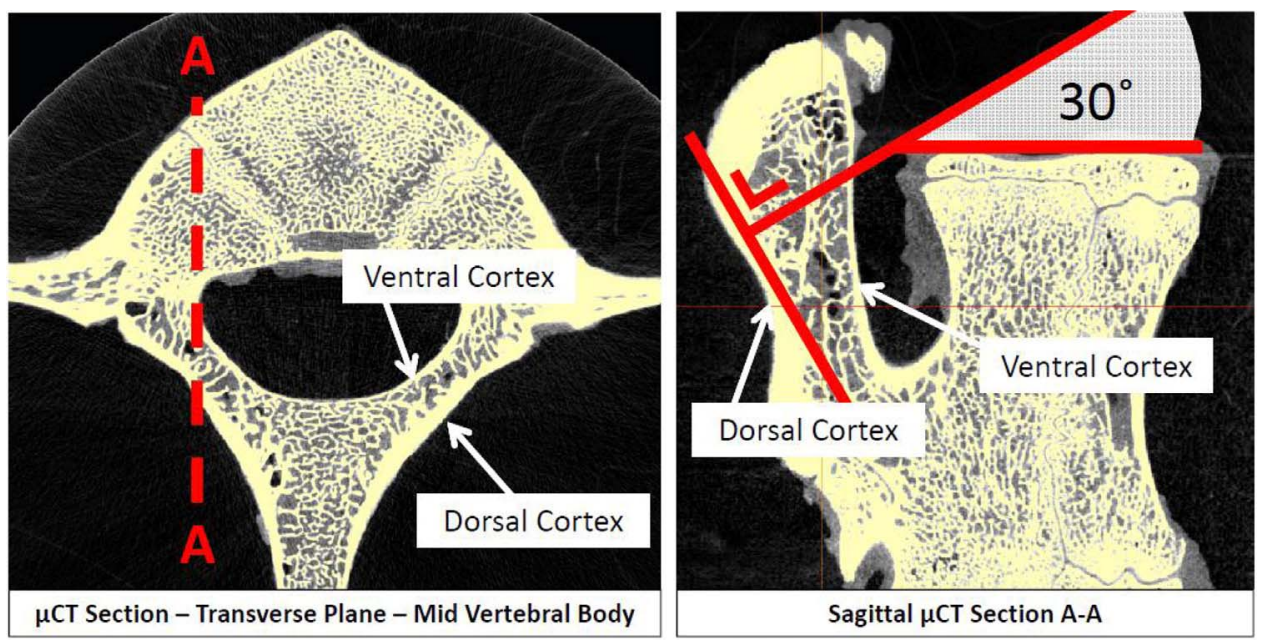

Fig. 1. Micro CT Section through a Porcine Vertebra Showing the Ventral and Dorsal Cortices Separated by Cancelous Bone - Scanned in inverted position. intervertebral disc (Fig. 1). In this plane, the extensor force can be divided between the left and right hand facet joints. If one of these facet joints is more coronally orientated the portion of extensor force on that side will be increased, thus the force acting in the posterior direction on that side will be greater than the less coronally orientated side.

While a considerable volume of work exists on the links between athletic technique and spondylolysis (Crewe, 2013; Annear, 1992; Jackson, 1981), particularly among athletes who participate in hyperextension sports, where a prevalence of $21 \%$ of spondylolysis has been recorded (Hoshina, 1980), the physical mechanisms causing spondylolysis remain unclear. It is clear from the increase in prevalence, between the normal paediatric population and those that are athletically active, that the fracture has a mechanical aetiology. Furthermore, individuals with one facet joint more coronally orientated than the other have been shown to be predisposed to unilateral spondylolysis (Masharawi, 2007; Rankine and Dickson, 2010; Crawford et al., 2015).

The hypothesis under investigation is that increased asymmetry of load on the facet surfaces leads to increased rates of damage and subsequent failure.

\section{Background theory}

Stress fractures in bone come about as a result of fatigue failure characterised by the growth and coalescence of short cracks. However, the bone tissue when observed during compression-compression cyclical testing moves through a number of loading phases from the initial linear elastic phase, through a yielding phase, followed by steady state creep (phase 3) before fracture (phase 4) (Gupta and Zioupos, 2008). During phase 1 , the bone material reacts in a reversible manner with no permanent alteration in form. During the yielding phase the material remains structurally intact, but plastic deformation occurs due to effects on multiple scale levels. Yielding effects such as the unwinding of tropocollagen molecules at the nano scale (Buehler, 2007), together with the breaking of bonds between adjacent mineralised collagen fibrils at the 10-100 nm scale (Gupta et al., 2006) and at a coarser $\mu \mathrm{m}$ scale the release and re-attachment of sacrificial bonds comprised of protein polymers acting as type of glue (Fantner et al., 2006), and finally at the $1-10 \mu \mathrm{m}$ scale, diffuse microcracking, the prevalent mechanism of microscale deformation. Fatigue cracks formed under uniaxial compressive loads form at an oblique angle to the line of loading (Carter and Hayes, 1976), together these multiscale effects work collectively to absorb energy and allow the development of diffuse microcracking damage at the expense of stiffness and residual strength (Gupta and Zioupos, 2008). During phase 3 which is observed as steady state creep, the laws of fracture mechanics take over. Many authors (Nalla et al., 2004; Koester et al., 2008; Ritchie et al., 2005) have shown crack resistance curve (R-curve) behaviour is dominant during this 3rd phase. R-curve behaviour is characterised by an increase in crack resistance (toughness) with crack extension and is known to be orientation dependent (Nalla et al., 2005). This rising R-curve behaviour is controlled by the three phenomena of microcracking, crack deflection and crack bridging by collagen fibrils working collectively to control the orientation dependence of toughness. It has also been observed that extrinsic toughening is the dominant mechanism, which, as stated by Ritchie (Ritchie, 1988) operates principally in the wake of the crack tip and acts to "shield" the crack from the applied driving force. The mechanism of short crack toughening due to bridging by collagen fibrils was also supported by the findings of Kruzic (Kruzic et al., 2006) in a study of surface cracks. Another toughening mechanism which must be considered is osteon pull-out. As the vertebral laminae also experience bending, the ventral surfaces are experiencing tensile cyclical loading. Osteonal de-bonding and pull-out has been identified as a toughening mechanism, whereby, osteons "telescope" out and bridge between adjacent crack surfaces before breaking (Hiller et al., 2003; Piekarski, 1970).

The experimental observation of these toughening mechanisms at work and their effect on material properties is the desired outcome of this paper. All of the mechanisms described are linked by their ability to absorb energy, Feltner, in 1960, summarised succinctly these energy absorbing phenomena as follows: "If a cyclically loaded material exhibited a perfectly linear elastic relationship between stress and strain, that is, if there is no deterioration of the elastic energy, the material would be resistant to fatigue fracture. The energy necessary to cause fracture is accumulated in small amounts during the course of the cyclic loading and is observable in terms of strain hysteresis." (Feltner and Morrow, 1961). Strain hysteresis is a measure of the absorbed plastic strain energy per fatigue cycle. For both cortical and trabecular bone it has been shown to increase with the number of applied fatigue cycles (Brouwers et al., 2009; Caler and Carter, 1989; Bowman et al., 1994). It manifests in 3 distinct phases during cyclical loading; the first phase is significant material property degradation, characterised by an increase in hysteresis, followed by a plateau phase before a further rapid increase in hysteresis immediately prior to fracture (Pattin et al., 1996). This increase in strain hysteresis is typically accompanied by a reduction in secant modulus brought about by the local yielding and creep mechanisms described previously (Dendorfer et al., 2009). The aetiology of stress fractures in bones has been shown to be repetitive high bone strains and strain rates (Fyhrie et al., 1998; Burr et al., 1996). Evidence also suggests that muscle contractions play a role in the alteration of bone strain patterns, particularly after muscle fatigue (Milgrom et al., 2007). These strains are essential to the repair and remodelling processes of bone, however the cyclical application of high strains has been linked with a loss of 


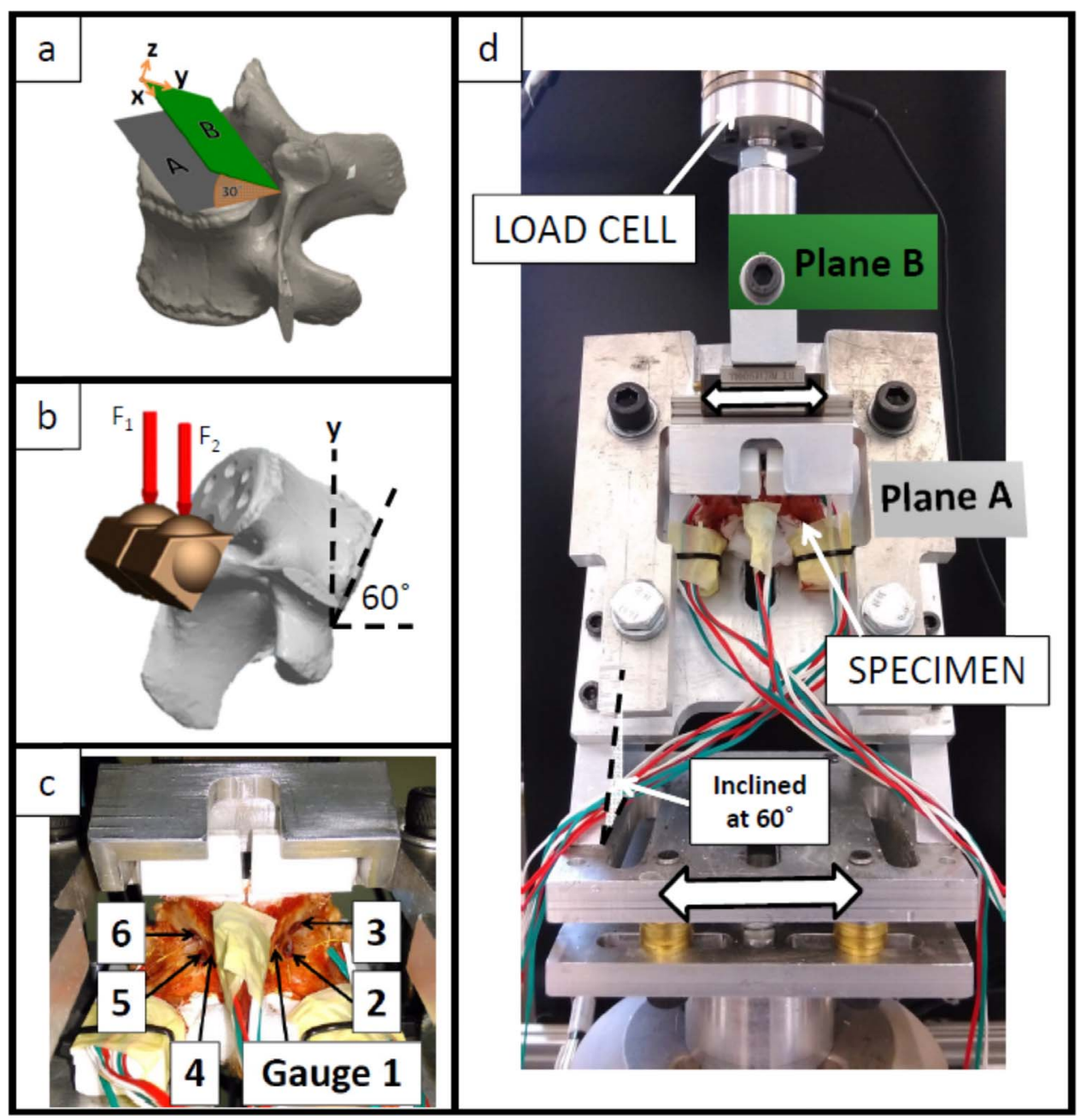

Fig. 2. a: Planes of loading through IV disc (A) and loading (B), b: Oblique view of specimen as mounted in apparatus, also showing cast PU loading domes, c: Posterior view of strain gauge locations on left and right hand laminae, d: Experimental apparatus.

material stiffness (Carter et al., 1981; Cotton et al., 2005), increase in hysteresis (Carter et al., 1981) and an increase in residual plastic strain (Winwood et al., 2006).

\section{Materials and methods}

\subsection{Specimens}

For this study, porcine lumbar vertebrae were selected, the 3rd, 4th \& 5th lumbar vertebrae from 10 different animals (6 months old), 21 specimens in total (several were rejected due to damage sustained during the butchering process). The vertebrae were dissected of all soft tissue including the facet surface cartilage, then cleaned using a scalpel, vertebral body endplates were left intact. The specimens were separated into 2 groups, the first 12 to be fitted with strain gauges, the remaining 9 to be prepared without gauges. The laminae surfaces were prepared for the fitting of strain gauges by cleaning with sandpaper (grade 400) and degreasing using Vishay GC-6 isopropyl alcohol. Three TML (Tokyo Sokki Kenkyujo Ltd.) $45^{\circ} / 90^{\circ}$ 3-Element Stacked Rosette gauges ( $\varnothing 4.5 \mathrm{~mm}$ ) were fitted on each side of the vertebral lamina, 6 in total (Fig. 2(c)). The gauges were fitted using cyanoacrylate adhesive (TML). Strain data was recorded using LabView C-Daq (National Instruments, TX, USA) data acquisition hardware.

A mould was manufactured in order to cast a specimen fixation material (polyurethane resin) around the 2 pieces of facet bone. The superior end of the vertebral body and superior facets were also fixed in cast polyurethane using an identical method (Fig. 2(b \& c)). Specimen hydration was maintained by placing saline soaked gauze inside the neural canal and around the pedicles.

\subsection{Test method}

In order to examine the response of the posterior portions of the vertebra it was necessary to load them in isolation. The method proposed by Cyron et al. (1976) was adapted whereby the fully intact vertebra is mounted, cranial end down, such that the facet surfaces are loaded on a plane $30^{\circ}$ from the plane of the IV disc. This plane is approximately perpendicular to the principal axis of the dorsal cortex of the pars interarticularis therefore applying load on this plane will induce bending in this cortex (Fig.s 1 and 2). The vertebral body of each specimen is secured in the test rig by way of four $4 \mathrm{~mm}$ tapered pins top and bottom which penetrate the end plates of the vertebral body. The loads (F1 \& F2) are applied to the cast polyurethane domed surfaces on each facet (Fig. 2(b)).

\subsection{Test loads}

Due to the effect of inter-specimen variability a method, similar to that used by Cristofolini et al. (Cristofolini et al., 2013), was used in order to establish a standard test load for each specimen. Strain levels were monitored as compressive loads were applied incrementally until the average strain $=1500 \mu \varepsilon$ across all gauges on a given specimen was reached. The load at $1500 \mu \varepsilon$ was taken to be the mean fatigue load with the upper and lower limits equal to $\pm 50 \%$ of that load. This load (always compressive) was applied cyclically at a rate of $2 \mathrm{~Hz}$. The remaining 9 specimens without rosette strain gauges were tested at 
Table 1

Specimen details, test loads \& test results.

\begin{tabular}{|c|c|c|c|c|c|c|c|}
\hline Specimen No. & Asymmetry & Animal Mass (kg) & Strain Recorded & Mean Load (N) & Load Amplitude (N) & Failed & $\mathrm{N}_{\mathrm{f}}$ (cycles) \\
\hline 492-L4 & $0^{\circ}$ & 76 & $\mathrm{Y}$ & -270 & 135 & $\mathrm{Y}$ & $675,000^{*}$ \\
\hline 493-L4 & $0^{\circ}$ & 85 & $\mathrm{Y}$ & -400 & 200 & $\mathrm{~N}$ & 200,000 \\
\hline 491-L3 & $0^{\circ}$ & 70 & $\mathrm{Y}$ & -300 & 150 & $\mathrm{~N}$ & 200,000 \\
\hline 311-L4 & $0^{\circ}$ & 67 & $\mathrm{Y}$ & -310 & 155 & $\mathrm{~N}$ & 200,000 \\
\hline S18-L4 & $0^{\circ}$ & 80 & $\mathrm{~N}$ & -400 & 200 & $\mathrm{~N}$ & 100,000 \\
\hline S52-L4 & $0^{\circ}$ & 90 & $\mathrm{~N}$ & -400 & 200 & $\mathrm{~N}$ & 100,000 \\
\hline S52-L5 & $0^{\circ}$ & 90 & $\mathrm{~N}$ & -400 & 200 & $\mathrm{~N}$ & 100,000 \\
\hline 492-L5 & $18^{\circ}$ & 76 & $\mathrm{Y}$ & -270 & 135 & $\mathrm{~N}$ & 200,000 \\
\hline 312-L4 & $18^{\circ}$ & 67 & $\mathrm{Y}$ & -430 & 215 & $\mathrm{~N}$ & 200,000 \\
\hline 492-L3 & $18^{\circ}$ & 76 & $\mathrm{Y}$ & -270 & 135 & $\mathrm{~N}$ & 200,000 \\
\hline 493-L3 & $18^{\circ}$ & 85 & $\mathrm{Y}$ & -400 & 200 & $\mathrm{~N}$ & 200,000 \\
\hline 311-L3 & $18^{\circ}$ & 67 & $\mathrm{~N}$ & -360 & 180 & $\mathrm{Y}$ & 36,900 \\
\hline S18I-L4 & $18^{\circ}$ & 80 & $\mathrm{~N}$ & -400 & 200 & $\mathrm{~N}$ & 100,000 \\
\hline S119-L5 & $18^{\circ}$ & 72 & $\mathrm{~N}$ & -400 & 200 & $\mathrm{~N}$ & 100,000 \\
\hline 489-L4 & $28^{\circ}$ & 70 & $\mathrm{Y}$ & -400 & 200 & $\mathrm{~N}$ & 200,000 \\
\hline 493-L5 & $28^{\circ}$ & 85 & $\mathrm{Y}$ & -400 & 200 & $\mathrm{Y}$ & 30,700 \\
\hline 313-L4 & $28^{\circ}$ & 65 & $\mathrm{Y}$ & -400 & 200 & $\mathrm{Y}$ & 24,300 \\
\hline 312-L5 & $28^{\circ}$ & 67 & $\mathrm{Y}$ & -430 & 215 & $\mathrm{Y}$ & 29,400 \\
\hline S52-L3 & $28^{\circ}$ & 90 & $\mathrm{~N}$ & -400 & 200 & $\mathrm{~N}$ & 100,000 \\
\hline S119-L3 & $28^{\circ}$ & 72 & $\mathrm{~N}$ & -400 & 200 & $\mathrm{~N}$ & 100,000 \\
\hline S119-L4 & $28^{\circ}$ & 72 & $\mathrm{~N}$ & -400 & 200 & $\mathrm{~N}$ & 100,000 \\
\hline
\end{tabular}

* Data truncated to 200,000 cycles for analysis.

$-400 \pm 200 \mathrm{~N}$. Table 1 gives details of the specimens used and the corresponding test loads.

\subsection{Facet angle asymmetry offsets}

Fig. 2(a) shows a schematic layout for the planes of loading. The predominant forces acting on the facet joints in the lower lumbar column are the sum of the force due to the upper body mass and the extensor muscles, both together called, in this case, the Extensor Force (F). This extensor force acts on a plane ' $\mathrm{B}$ ' orientated $30^{\circ}$ from the plane of the IV disc, plane ' $\mathrm{A}$ '. The assumption is that this force is equally apportioned to each facet and acts normal to the surface of the facet. Since each facet surface is at a different angle, it is possible to calculate the forces on plane ' $\mathrm{B}$ ' acting in the $\mathrm{Y}$ direction (parallel to the sagittal plane) for each facet as:

$F_{1}=(F / 2) \cos \theta_{1}$

And

$F_{2}=(F / 2) \cos \theta_{2}$

The ratio of forces acting in direction $\mathrm{y}$ is equal to $\frac{\cos \theta_{2}}{\cos \theta_{1}}=\frac{F_{2}}{F_{1}}$ Equation 1

Facet angle asymmetry values were found by measuring clinical CT scans, where the facet angle is defined as the angle (on plane ' $\mathrm{A}$ ') between the surface of the facet and the coronal plane (Table 1 ). From this data a medium level of facet angle asymmetry equal to $18^{\circ}$ difference between facets, and a maximum level of facet angle asymmetry equal to $28^{\circ}$ of difference were defined. This gives maximum load ratio (F2/F1) of 1.75 for $18^{\circ}$ of facet angle asymmetry and 3.34 for $28^{\circ}$ of facet angle asymmetry. The test apparatus was designed such that the base could be adjusted in the transverse direction. This adjustment allows the point of loading to be displaced either left or right in order to mimic the effects of facet angle asymmetry. The actuator that applies the load to the facets was mounted on a lug and clevis assembly to facilitate rotation in plane ' $\mathrm{B}$ ' and a linear slide bearing to allow lateral displacement (Fig. 2d). A load cell (ATI Mini45 Force/Torque) was mounted above the lug and clevis and secured to the test machine (MTS Bionix). The maximum offset for the apparatus was $7 \mathrm{~mm}$ giving a load ratio (F2/F1) of 3.33 , equivalent to $28^{\circ}$ of facet angle asymmetry, an intermediate offset was also chosen at $3.5 \mathrm{~mm}$ giving a load ratio of 1.74 , equivalent to $17.73^{\circ}$ of facet angle asymmetry.

\subsection{Steady state creep rate (SSCR)}

The steady state creep rate was calculated by measuring the slope of the secondary phase of each creep displacement plot. The beginning of the secondary creep phase was defined as the point at which the rate of change of the tangent slope is minimised to a value equal to twice the final calculated value. This was calculated by examining just the primary and secondary creep phases, carrying out a Log-Log transformation, and using linear regression to find the slope and intercept of the resulting plot. This allowed the formulation of a function describing the 1st and 2nd creep phase, for which the 2nd derivative was calculated. This methodology allowed the accurate identification of the 2nd creep phase from which a slope was calculated for each specimen.

\subsection{Strain}

Strain data was recorded for each gauge element, 3 elements per gauge, and 6 gauges per vertebra. From this recorded data the principal strain values $\varepsilon_{1}$ and $\varepsilon_{2}$ were calculated. This calculated strain was then averaged over the 3 strain rosettes on each lamina (Left and Right) giving a measure of the state of strain over the area circumscribed by the gauges. This lamina strain for each specimen was then averaged for all those within each facet angle asymmetry level grouping.

\subsection{Hysteresis}

The displacement and strain hysteresis measurements were defined as the difference in area under the curve between the loading and unloading portions of their respective plots. The data in each case is treated as a 1 dimensional array of numbers, from which a peak to peak sub array is selected. This sub array is divided at the minimum value (valley) between the peaks into two 1 dimensional arrays, each of which is integrated and subtracted. If the bone material has a perfectly linear elastic relationship, the subtraction of these integrals should equal zero. Any difference between them is a measure equivalent to the absorbed plastic strain energy. Calculations are carried out at equally spaced Life fractions $\left(\mathrm{N} / \mathrm{N}_{\mathrm{f}}\right)$ for each specimen.

\subsection{Secant modulus}

The secant modulus was defined as $\Delta N / \Delta m m$ at a particular life 


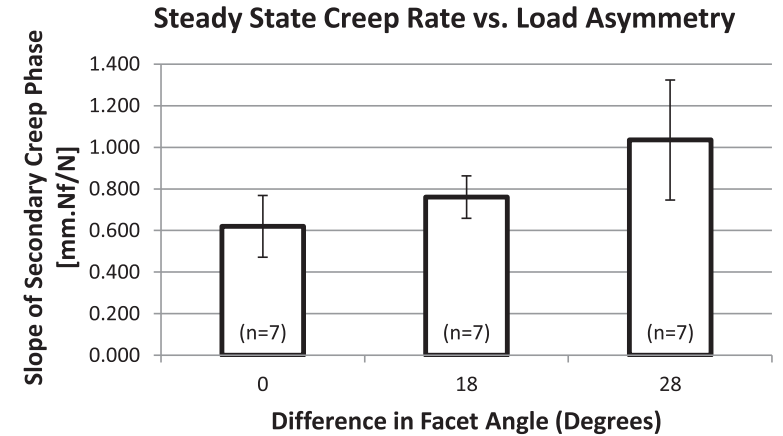

Fig. 3. Steady State Creep Rate (SSCR) for porcine specimens during cyclical compression tests.

fraction $\left(\mathrm{N} / \mathrm{N}_{\mathrm{f}}\right)$. The data was recorded using an MTS Bionix servohydraulic test machine. Analysis focussed on the reduction in secant modulus during the steady state creep phase $\left(0.35<\mathrm{N} / \mathrm{N}_{\mathrm{f}}<0.8\right)$. The recorded data was normalised for ease of comparison.

All measurements and calculations were carried out using a series of custom built virtual instruments (National Instruments LabView). The results of the calculations were plotted using MS Excel.

\section{Results}

\subsection{Steady state creep rate}

The change in steady state creep rate (SSCR) demonstrated that as apportionment of load between facets is altered, the SSCR increases by $23 \%$ at the intermediate level $\left(18^{\circ}\right)$ of facet angle asymmetry, and by $67 \%$ at the maximum level $\left(28^{\circ}\right)$ of facet angle asymmetry (Fig. 3 ). This change in steady state creep rate as a result of increasing load asymmetry is statistically significant with $\mathrm{p}=0.036(\mathrm{a}=0.05)$. Creep plots for each level of asymmetry are presented in Fig. 7.

\subsection{Strain}

The average maximum principal strain $\left(\varepsilon_{1}\right.$ and $\left.\varepsilon_{2}\right)$ values are presented in Fig. 4 where a clear dominance in compressive principal strain is displayed with average values between $4000 \mu \varepsilon$ and $6000 \mu \varepsilon$ in comparison to tensile principal strain values of $1000 \mu \varepsilon$ to $2500 \mu \varepsilon$. Compressive strain values show a decreasing trend with increasing asymmetry on both the left and right hand side, conversely the tensile strain values show an increasing trend. No statistical significance was calculated with p-values all $>0.05$.

Fig. 5 is comprised of the compressive strain results, measured against life fraction $\left(\mathrm{N} / \mathrm{N}_{\mathrm{f}}\right)$ for left (lower load) and right (higher load) pars interarticularis and for each level of angular difference from $0^{\circ}$ (Top), $18^{\circ}$ (Middle) to $28^{\circ}$ (Bottom). The compressive principal strain values for $0^{\circ}$ (Top) and $18^{\circ}$ (Middle) conform to a well fitted log shape

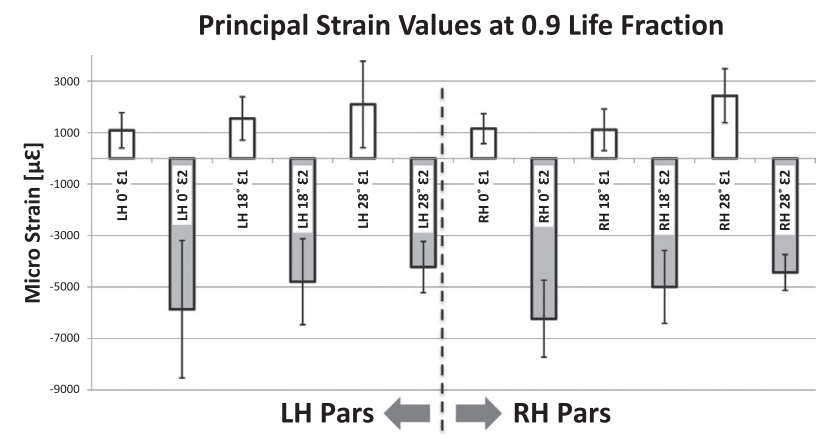

Fig. 4. Tensile and compressive principal strain values for each level of facet angle asymmetry, RH Pars was the highly loaded side.
$\left(\mathrm{R}^{2}>0.91\right.$ for all). The 2 plots relating to the maximum level of asymmetry are not as well fitted with $\mathrm{R}^{2}=0.87(\mathrm{LH})$ and $\mathrm{R}^{2}=0.9$ (RH).

\subsection{Strain range}

The results for the intermediate level $\left(18^{\circ}\right)$ of facet angle asymmetry displayed little difference (4\%) between the strain range on left hand pars $(930 \mu \varepsilon)$ interarticularis and the right hand pars $(970 \mu \varepsilon)$. The maximum level $\left(28^{\circ}\right)$ of facet angle asymmetry, particularly for the 3 out of 4 specimens that failed (Fig. 6) where the strain range in the right hand pars exceeded the left by $26 \%(420 \mu \varepsilon)$. The average strain range on each side is constant during the yield and steady state creep phase until $\mathrm{N} / \mathrm{N}_{\mathrm{f}}=0.5$ when the strain range on the left pars begins to increase, this increase continues until $\mathrm{N} / \mathrm{N}_{\mathrm{f}}=0.9$ when a marked increase in left pars range is observed together with a slight dip in the right pars before specimen failure.

\subsection{Secant modulus}

Secant modulus reduction rate for the steady state creep phase was calculated showing positive slopes with a large degree of scatter for reference level $\left(0^{\circ}\right)$ with slope $=27\left[(\mathrm{~N} / \mathrm{mm}) /\left(\mathrm{N} / \mathrm{N}_{\mathrm{f}}\right)\right]$ and standard deviation of $35\left[(\mathrm{~N} / \mathrm{mm}) /\left(\mathrm{N} / \mathrm{N}_{\mathrm{f}}\right)\right]$ and the intermediate level $\left(18^{\circ}\right)$ slope $=32(\mathrm{SD}=63)$. The plot for the maximum $\left(28^{\circ}\right)$ level of facet angle asymmetry shows a negative average slope of $-30\left[(\mathrm{~N} / \mathrm{mm}) /\left(\mathrm{N} / \mathrm{N}_{\mathrm{f}}\right)\right]$ accompanied by a large variance ( $\mathrm{SD}=139)$. No statistical significance was calculated for the relationship between the increase in facet angle and difference and secant modulus reduction rate $\mathrm{p}=0.429$ ( $\mathrm{a}=$ 0.05).

\subsection{Hysteresis}

The results for hysteresis are examined alongside the results for creep. Fig. 7 shows 6 plots in total, the vertical dash line represents the average transition to the steady state creep phase. This transition occurs at approximately the same point for the reference level $\left(0^{\circ}\right)$ and the intermediate level $\left(18^{\circ}\right), \mathrm{N} / \mathrm{N}_{\mathrm{f}}=0.35$; however for the maximum level $\left(28^{\circ}\right)$ of facet angle asymmetry this transition occurs at a life fraction $\left(\mathrm{N} / \mathrm{N}_{\mathrm{f}}\right)$ of 0.42 , albeit with significantly shorter cycles to failure (Results). The left hand column shows the characteristic creep curve for each level of facet angle asymmetry. A clear primary and secondary creep phase is visible for the reference level $\left(0^{\circ}\right)$ and the intermediate level $\left(18^{\circ}\right)$ representing the initial linear elastic and yielding phase together with the steady state creep phase. The creep curve for the maximum level $\left(28^{\circ}\right)$ of facet angle asymmetry shows a tertiary phase relating to the fracture of the specimens. The error bars show a wide degree of scatter for the reference level $\left(0^{\circ}\right)$ which diminishes for the 2 following plots, showing a tighter grouping during the yielding phase before diverging during steady state creep.

The second column of plots are the force-displacement hysteresis where the results for each level of facet angle asymmetry display a good fit to a $\log$ trend with $\mathrm{R}^{2}>0.89$ for all 3 levels of facet angle asymmetry. The slope of the linear phase of each plot was measured between $\mathrm{N} / \mathrm{N}_{\mathrm{f}}=0.5$ and 0.85 with a significant $(\mathrm{p}=0.026)$ increases of $12 \%$ between the reference level $\left(0^{\circ}\right)$ and the intermediate level $\left(18^{\circ}\right)$ and $50 \%$ between the reference level $\left(0^{\circ}\right)$ and the maximum level of facet angle asymmetry.

\subsection{Summary table of results}

See Table 2 and 3.

\section{Discussion}

Cyclical compression tests were carried out on 3 batches of 

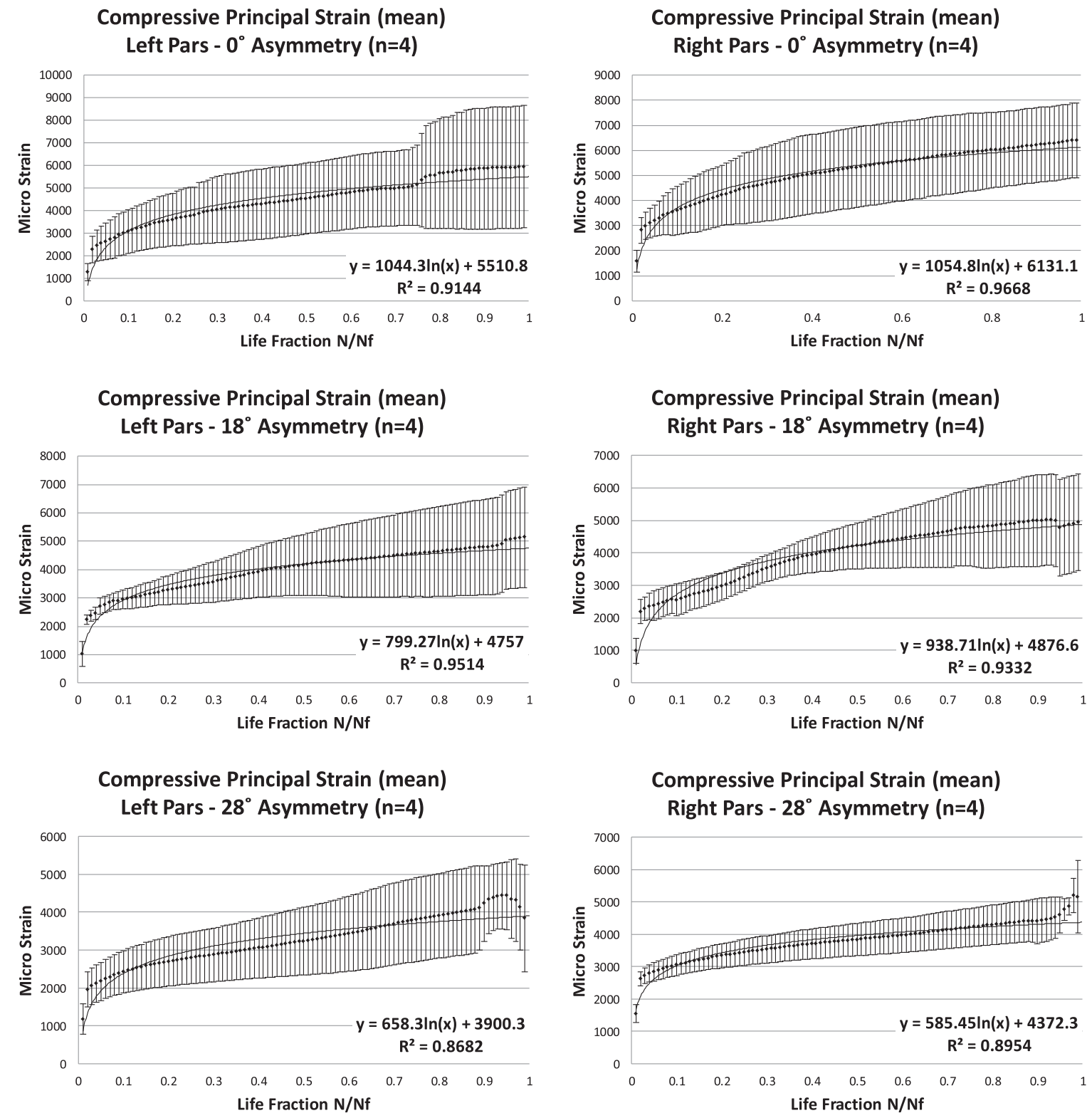

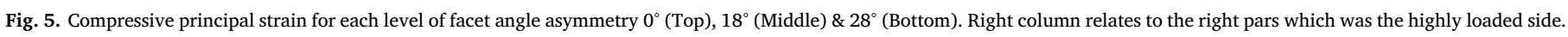

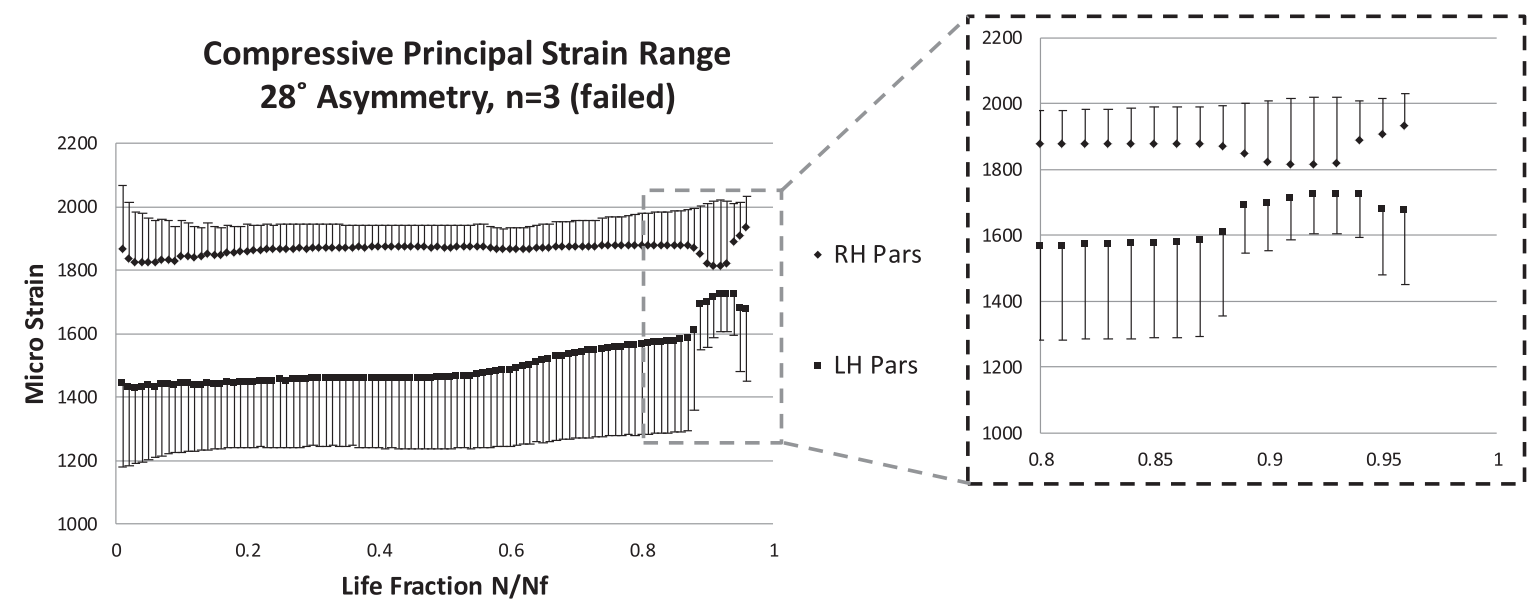

Fig. 6. Strain range at maximum level of facet angle asymmetry, RH Pars was the highly loaded side. 

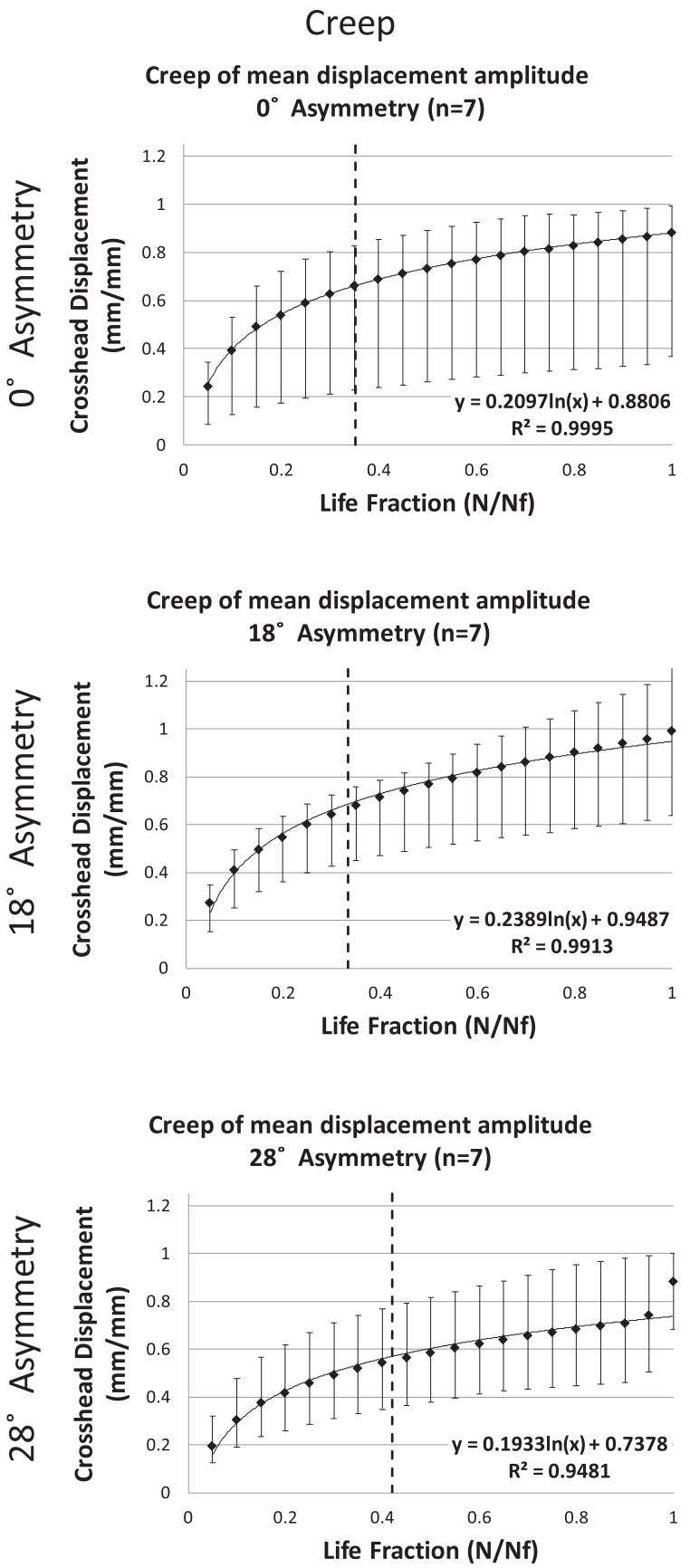

\section{Force-Displacement Hysteresis}

Force-Displacement Hysteresis vs. Life Fraction at $0^{\circ}$ Asymmetry $(n=7)$

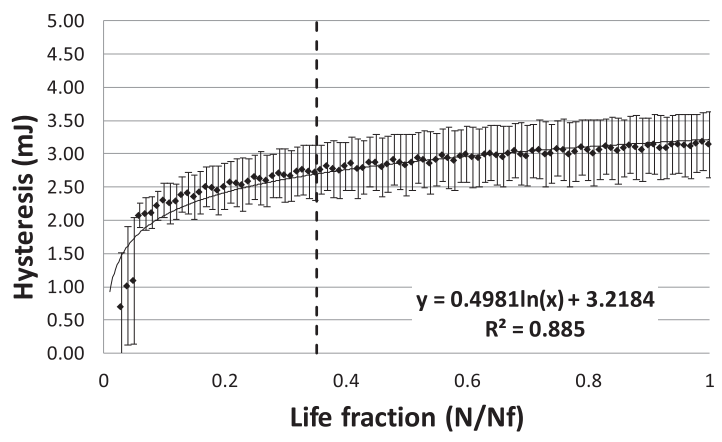

Force-Displacement Hysteresis vs. Life Fraction at $18^{\circ}$ Asymmetry $(n=7)$

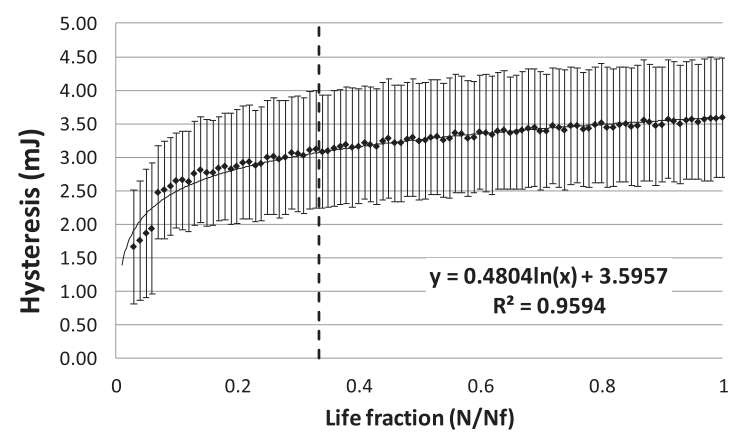

Force-Displacement Hysteresis vs. Life Fraction at $28^{\circ}$ Asymmetry $(n=7)$

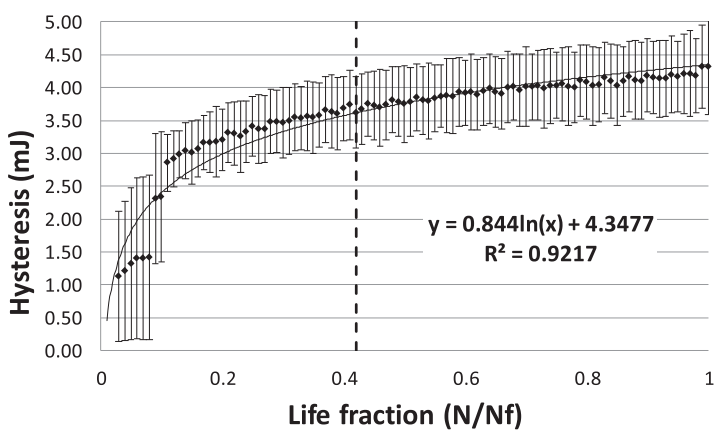

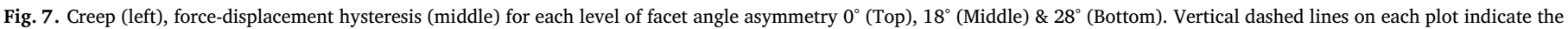
beginning of the steady state creep phase.

Table 2

Summary of results calculated for life fraction $\left(0.35<\mathrm{N} / \mathrm{N}_{\mathrm{f}}<0.8\right)$ : Steady state creep rate (SSCR), secant modulus degradation and hysteresis rate.

\begin{tabular}{|c|c|c|c|c|c|c|}
\hline Asymmetry & $\begin{array}{l}\text { Steady } \\
\text { State } \\
\text { Creep } \\
\text { Rate } \\
{[(\mathrm{mm}) /} \\
(\mathrm{N} / \mathrm{Nf})]\end{array}$ & SD & $\begin{array}{l}\text { Steady State } \\
\text { Modulus } \\
\text { Degradation } \\
{[(\mathrm{N} / \mathrm{mm}) /(\mathrm{N} /} \\
\mathrm{Nf})]\end{array}$ & SD & $\begin{array}{l}\text { Steady State } \\
\text { Hysteresis Rate } \\
\text { [(Hysteresis)/ } \\
\text { (N/Nf)] }\end{array}$ & SD \\
\hline $0^{\circ}$ & 0.62 & 0.15 & 27 & 35 & 0.57 & 0.15 \\
\hline $18^{\circ}$ & 0.76 & 0.10 & 32 & 63 & 0.64 & 0.10 \\
\hline $28^{\circ}$ & 1.04 & 0.29 & -30 & 139 & 0.86 & 0.24 \\
\hline p-value & 0.026 & - & 0.429 & - & 0.036 & - \\
\hline
\end{tabular}

specimens, on which the effects of bone facet angle asymmetry were simulated. When the fatigue cycle $\left(\mathrm{N}_{\mathrm{f}}\right)$ results in Table 1 are analysed, where only 5 out of the 21 specimens failed it is clear that the majority failed at the maximum level of asymmetry, however it is not possible to state that this is a significant result $(\mathrm{p}=0.153)$. When just the specimens at the maximum level $\left(28^{\circ}\right)$ of asymmetry are considered in isolation, 3 out of 7 specimens failed at $\mathrm{N}_{\mathrm{f}} \leq 30,700$, this reduction in fatigue life could be due to the effects of torsion as shown previously by Taylor (Taylor et al., 2003), induced in this case as a result of the load offset whereby the specimen begins to twist away from the point of maximum load inducing a torsional load.

\subsection{Steady state creep rate}

Steady state creep results were analysed for each level of facet angle 
Table 3

Summary of strain results calculated at life fraction $\mathrm{N} / \mathrm{Nf}=0.9$ (pre-failure maximum).

\begin{tabular}{|c|c|c|c|c|c|c|c|c|c|c|c|}
\hline \multicolumn{6}{|c|}{ LH Pars $[\mu \varepsilon]$} & \multicolumn{6}{|c|}{ RH Pars $[\mu \mathcal{E}]$} \\
\hline $0^{\circ} \varepsilon_{1}$ & $0^{\circ} \mathcal{E}_{2}$ & $18^{\circ} \varepsilon_{1}$ & $18^{\circ} \varepsilon_{2}$ & $28^{\circ} \varepsilon_{1}$ & $28^{\circ} \varepsilon_{2}$ & $0^{\circ} \varepsilon_{1}$ & $0^{\circ} \varepsilon_{2}$ & $18^{\circ} \varepsilon_{1}$ & $18^{\circ} \varepsilon_{2}$ & $28^{\circ} \varepsilon_{1}$ & $28^{\circ} \varepsilon_{2}$ \\
\hline 1089 & -5862 & 1548 & -4790 & 2092 & -4227 & 1153 & -6232 & 1109 & -4995 & 2429 & -4435 \\
\hline 685 & 2673 & 841 & 1671 & 1679 & 999 & 583 & 1493 & 804 & 1410 & 1046 & 698 \\
\hline
\end{tabular}

asymmetry. At the reference level $\left(0^{\circ}\right)$ a large degree of scatter is present $(\mathrm{SD}=0.15)$, this is due to inter-specimen variability. This scatter is reduced at the intermediate level of facet angle asymmetry (SD = 0.1 ) However, at the maximum level of facet angle asymmetry the scatter increases once more $(S D=0.29)$ due mainly to an outlier specimen (313-L4) without which the standard deviation would be in keeping with the intermediate level of facet angle asymmetry. It is important to note that the creep data is recorded using a uniaxial test machine, therefore it is a global measurement for the specimen (both facets). The overall increase in slope magnitude is $50 \%$, this is significant as it comes about not as a result of an increase in force, but instead as a result of increased asymmetry of load on the facet surfaces. It should also be noted that steady state creep rate (SSCR) has a positive linear correlation with the steady state damage rate $\left(R^{2}=0.90\right)$, this is expected as creep displacements must result from accrued specimen damage.

\subsection{Strain measurements}

The pars interarticularis, having a "sandwich bone"(Currey, 1984) type of structure is undergoing bending when the facets are loaded. The ventral surface (facing the abdomen) of this bone segment should therefore be in tension and the dorsal surface in compression as shown by Shah (Shah et al., 1978). The ventral surface of these specimens was not accessible with strain gauges, however, when the principal strain values calculated for the rosette gauges placed on the dorsal surface were analysed; a strong dominance in compression was observed (Fig. 4). At each level of facet angle asymmetry $\left(0^{\circ}\right.$ to $\left.28^{\circ}\right)$ the principal compressive strain $\left(\varepsilon_{2}\right)$ was greater than its tensile counterpart $\left(\varepsilon_{1}\right)$. The maximum values recorded for compressive principal strain (all 6 gauges) at each facet angle asymmetry level $\left(0^{\circ}, 18^{\circ} \& 28^{\circ}\right)$ were $6200 \mu \varepsilon, 5000 \mu \varepsilon$ and $4400 \mu \varepsilon$ respectively, with differences between the left and right hand laminae of $6.3 \%, 4.3 \%$ and $4.9 \%$ in favour of the highly loaded side respectively. The magnitude of compressive principal strain reduces by $\approx 1800 \mu \mathcal{E}$ with increasing asymmetry. Strain is known to be the dominant force in crack initiation in bone (Nalla et al., 2005) and reduction in cycles to failure is known to be determined by strain range (Carter et al., 1981). The strain range on the highly loaded pars (right) is $26 \%$ higher than the side with the lower load (Fig. 6) therefore the driving force for crack growth is greater on this side. Fig. 5 (facet angle $\Delta=28^{\circ}$ ) supports this assertion with the right side leading in terms of strain magnitude at each life fraction $\left(\mathrm{N} / \mathrm{N}_{\mathrm{f}}\right)$ up to fracture with a redistribution of strain in the final $10 \%$ of life due to fracturing of the right hand pars and the subsequent increase of load on the left pars.

\subsection{Hysteresis}

It is clear from the results thus far that asymmetrical loading of bone brings about a number of interesting results, particularly when related to an increase in torsion loading which is known to increase the level of microcracking (Taylor et al., 2003; Fatihhi et al., 2016), the prevalent mechanism of microscale deformation. This, along with other extrinsic toughening mechanisms work to absorb energy and reduce stiffness and residual strength (Nalla et al., 2005; Gupta and Zioupos, 2008). This work has utilised 2 methods to quantify this energy absorption, the first method measures the Force-Displacement hysteresis where Pattin (Pattin et al., 1996) describes the energy absorption (hysteresis) occurring in 3 distinct phases, an initial rapid increase followed by a plateau before a further increase to fracture. This 3-phase pattern is visible for all levels of facet angle asymmetry where the transition to the plateau phase coincides with the beginning of steady state creep. Results in Fig. 7 display an initial rapid increase in energy absorption related to yielding mechanisms described previously. This moderates into the plateau phase where the intrinsic and extrinsic toughening mechanisms work in opposition to control microcrack length (Nalla et al., 2006; Koester et al., 2008; Ritchie et al., 2005) and energy is much more slowly accumulated, before finally the growth and coalescence of these diffuse microcracks becomes the beginning of a fracture and the energy absorbed increases rapidly before final fracture. What is of particular interest is the step increase in the level of energy absorbed as the level of facet angle asymmetry is increased, between $0^{\circ}$ and $18^{\circ}$ there is an $11 \%$ increase, with a further $20 \%$ between $18^{\circ}$ and $28^{\circ}$. This indicates that increasing asymmetry of load leads to increased damage.

The second hysteresis method utilised was compressive principal strain hysteresis; Fig. 8 shows an analysis of specimen 493-L5, this specimen was tested at $28^{\circ}$ of asymmetry and failed at 30,700 cycles. The results displayed are calculated using the data from a single strain gauge (No. 3) showing the relationship between mean compressive principal strain $\left(\varepsilon_{2}\right)$, strain range, compressive strain hysteresis and the associated damage to the bone directly beneath the strain gauge. The applied force amplitude is fixed at $200 \mathrm{~N}$ therefore changes in the measured strain magnitude and range is due to damage and the associated specimen creep. The damage is represented by absorption of energy quantified in the hysteresis plot which has a positive linear correlation $\left(\mathrm{R}^{2}=0.91\right)$ with mean compressive strain and a negative correlation with strain range $\left(\mathrm{R}^{2}=0.86\right)$. This shows that as damage is accrued and the bone stiffness is reduced, the mean strain increases and the measured strain range is reduced.

\section{Conclusion}

The data presented herein describes a complex set of mechanisms that occur during the yielding and creep phases of cyclical compression tests. Inclusion of facet angle asymmetry together with the use of intact vertebrae broadens the knowledge on the subject of the spondylolysis stress fracture, but is also applicable to any stress fracture in bone particularly in the presence of asymmetrical loading. This is applicable in particular to the study of scoliosis and hip joint loading in patients with altered gait after stroke.

The principal conclusions of this paper are that differences in facet angle lead to an asymmetry of loading in the facet joints; this in turn leads to an initial increase in strain on the side with the more coronally orientated facet. The strain amplitude, which is the driving force for crack propagation, is greater on this side at all times up to fracture, the effects of which can be observed in the increase in steady state creep rate and the increase in yielding and toughening mechanisms that take place, quantified by the force-displacement and compressive principal strain hysteresis. These results confirm the hypothesis that increased asymmetry of load on the facet surfaces leads to increased rates of damage and subsequent failure. 
493-L5 Principal Compressive Strain Mean

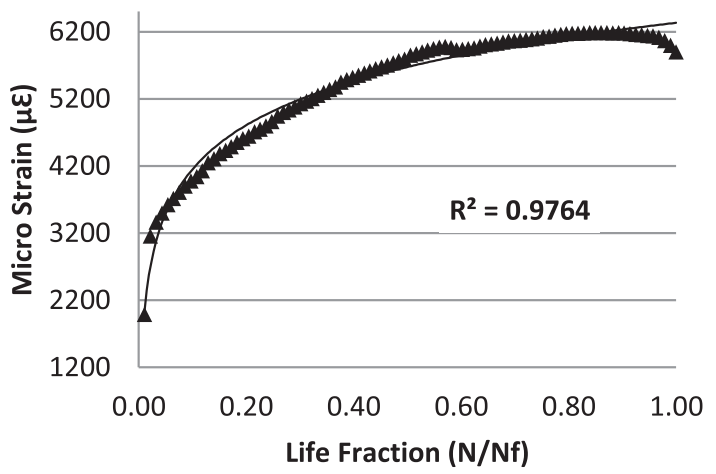

493-L5 Principal Compressive Strain Hysteresis

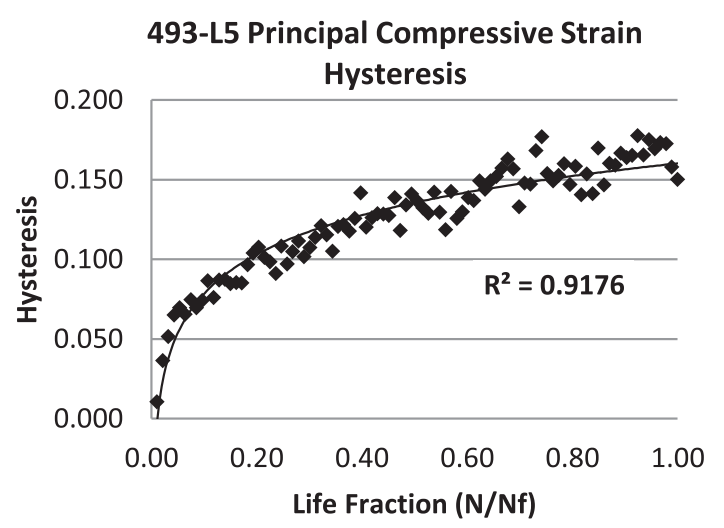

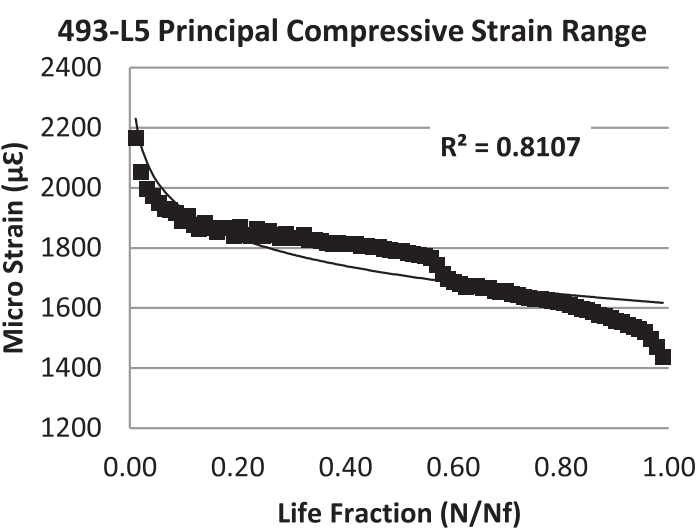

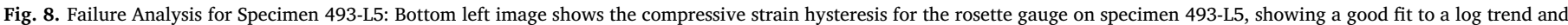

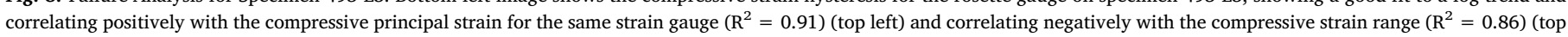
right).

\section{Acknowledgment}

The authors would like to thank the following people for their assistance with this study:

1. Dr Gerard Sheridan of Tallaght Hospital (AMNCH) for his assistance in sourcing the patient data.

2. Ms Betty Byrne of Byrne's Butchers in Camolin, Wexford for the free range porcine spinal specimens.

Funded under the Irish Research Council Embark Award Scheme, RS/2012/318.

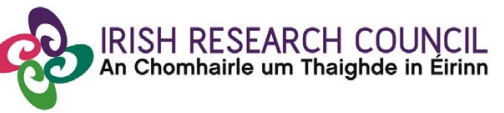

\section{References}

Annear, 1992. Pars interarticularis stress and disc degeneration, cricket's potent strike force: the fast bowler. ANZ J. Surg. 62, 768-773.

Beutler, W.J., Fredrickson, B.E., Murtland, A., Sweeney, C.A., Grant, W.D., B.D, 2003. The natural history of spondylol- ysis and spondylolisthesis: 45-year follow-up evaluation. Spine (Phila. Pa. 1976) 28, 1027-1035.

Bowman, S., Keaveny, T., Gibson, L., Hayes, W., McMahon, T., 1994. Compressive creep behavior trabecular. J. Biomech. 27, 301-310.

Brouwers, J.E.M., Ruchelsman, M., Rietbergen, B.V., Bouxsein, M.L., 2009. Determination of rat vertebral bone compressive fatigue properties in untreated intact rats and zoledronic-acid-treated, ovariectomized rats. Osteoporos. Int. 20, 1377-1384. http:// dx.doi.org/10.1007/s00198-008-0803-z.

Buehler, M.J., 2007. Molecular nanomechanics of nascent bone: fibrillar toughening by mineralization. Nanotechnology 18, 295102. http://dx.doi.org/10.1088/0957-4484/ $18 / 29 / 295102$

Burr, D.B., Milgrom, C., Fyhrie, D., Forwood, M., Nyska, M., Finestone, A., Hoshaw, S., Saiag, E., Simkin, A., 1996. In vivo measurement of human tibial strains during vigorous activity. Bone 18, 405-410. http://dx.doi.org/10.1016/8756-3282(96)
00028-2.

Caler, W.E., Carter, D.R., 1989. Bone creep-fatigue damage accumulation. J. Biomech. 22, 625-635. http://dx.doi.org/10.1016/0021-9290(89)90013-4.

Carter, D.R., Hayes, W.C., 1976. Compact bone fatigue damage. Clin. Orthop. Relat. Res. Carter, D.R., Caler, W.E., Spengler, D.M., Frankel, V.H., 1981. Fatigue behavior of adult cortical bone: the influence of mean strain and strain range. Acta Orthop. Scand. 52, 481-490.

Cotton, J.R., Winwood, K., Zioupos, P., Taylor, M., 2005. Damage rate is a predictor of fatigue life and creep strain rate in tensile fatigue of human cortical bone samples. J. Biomech. Eng. 127, 213-219. http://dx.doi.org/10.1115/1.1865188.

Crawford, C.H., Ledonio, C.G.T., Bess, R.S., Buchowski, J.M., Burton, D.C., Hu, S.S., Lonner, B.S.H., Polly, D.W., Smith, J.S., Sanders, J.O., 2015. Current evidence regarding the etiology, prevalence, natural history, and prognosis of pediatric lumbar spondylolysis: a report from the scoliosis research society evidence-based medicine committee. Spine Deform. 3, 12-29. http://dx.doi.org/10.1016/j.jspd.2014.06.005.

Crewe, H., 2013. Lumbo-pelvic loading during fast bowling in adolescent cricketers: the influence of bowling speed and technique. J. Sports Sci. 31, 1082-1090.

Cristofolini, L., Brandolini, N., Danesi, V., Juszczyk, M.M., Erani, P., Viceconti, M., 2013. Strain distribution in the lumbar vertebrae under different loading configurations. Spine J. 13, 1281-1292. http://dx.doi.org/10.1016/j.spinee.2013.06.014.

Currey, J.D., 1984. Comparative mechanical properties and histology of bone. Integr. Comp. Biol. 24, 5 .

Cyron, B.M., Hutton, W.C., Troup, J.D., 1976. Spondylolytic fractures. J. Bone Jt. Surg. 58-B, 462-466.

Dendorfer, S., Maier, H.J., Hammer, J., 2009. Fatigue damage in cancellous bone: an experimental approach from continuum to micro scale. J. Mech. Behav. Biomed. Mater. 2, 113-119. http://dx.doi.org/10.1016/j.jmbbm.2008.03.003.

Fantner, G.E., Oroudjev, E., Schitter, G., Golde, L.S., Thurner, P., Finch, M.M., Turner, P., Gutsmann, T., Morse, D.E., Hansma, H., Hansma, P.K., 2006. Sacrificial bonds and hidden length: unraveling molecular mesostructures in tough materials. Biophys. J. 90, 1411-1418. http://dx.doi.org/10.1529/biophysj.105.069344.

Fatihhi, S.J., Rabiatul, A.A.R., Harun, M.N., Kadir, M.R.A., Kamarul, T., Syahrom, A., 2016. Effect of torsional loading on compressive fatigue behaviour of trabecular bone. J. Mech. Behav. Biomed. Mater. 54, 21-32. http://dx.doi.org/10.1016/j. jmbbm.2015.09.006.

Feltner, C.E., Morrow, J.D., 1961. Microplastic strain hysteresis energy as a criterion for fatigue fracture. J. Basic Eng. 83, 15. http://dx.doi.org/10.1115/1.3658884.

Frost, H.M., 2004. A 2003 update of bone physiology and Wolff's law for clinicians. Angle Orthod. 74, 3-15.

Fyhrie, D.P., Milgrom, C., Hoshaw, S.J., Simkin, a., Dar, S., Drumb, D., Burr, D.B., 1998 Effect of fatiguing exercise on longitudinal bone strain as related to stress fracture in 
humans. Ann. Biomed. Eng. 26, 660-665. http://dx.doi.org/10.1114/1.103.

Gupta, H.S., Zioupos, P., 2008. Fracture of bone tissue: the "hows" and the "whys. Med. Eng. Phys. 30, 1209-1226. http://dx.doi.org/10.1016/j.medengphy.2008.09.007.

Gupta, H.S., Wagermaier, W., Zickler, G.A., Hartmann, J., Funari, S.S., Roschger, P., Wagner, D.H., Fratzl, P., 2006. Fibrillar level fracture in bone beyond the yield point. Int. J. Fract. 139, 425-436. http://dx.doi.org/10.1007/s10704-006-6635-y.

HensingerRN, 1989. Spondylolysis and spondylolisthesis in children and adolescents. J. Bone Jt. Surg. 71, 1098-1107.

Hiller, L.P., Stover, S.M., Gibson, V.A., Gibeling, J.C., Prater, C.S., Hazelwood, S.J., Yeh, O.C., Martin, R.B., 2003. Osteon pullout in the equine third metacarpal bone: effects of ex vivo fatigue. J. Orthop. Res. 21, 481-488. http://dx.doi.org/10.1016/S07360266(02)00232-2.

Hoshina, H., 1980. Spondylolysis in athletes. Phys. Sports Med. 8, 75-79.

Jackson, D.W., 1976. Spondylolysis in the female gymnast. Clin. Orthop. Relat. Res. 68-73.

Jackson, D.W., 1981. Stress reactions involving the pars interarticularis in young athletes. Am. J. Sports Med. 9, 304-312.

Koester, K.J., Ager, J.W., Ritchie, R.O., Ager III, J.W., Ritchie, R.O., 2008. The true toughness of human cortical bone measured with realistically short cracks. Nat. Mater. 7, 672-677. http://dx.doi.org/10.1038/nmat2221.

Kruzic, J.J., Scott, J. a., Nalla, R.K., Ritchie, R.O., 2006. Propagation of surface fatigue cracks in human cortical bone. J. Biomech. 39, 968-972. http://dx.doi.org/10.1016/ j.jbiomech.2005.01.025.

Masharawi, Y.M., 2007. Lumbar facet orientation in spondylolysis: a skeletal study. Spine (Phila., Pa. 1976) 32, E176-E180.

Masharawi, Y.M., Alperovitch-Najenson, D., Steinberg, N., Dar, G., Peleg, S., Rothschild, B., Salame, K., Hershkovitz, I., 2007. Lumbar facet orientation in spondylolysis: a skeletal study. Spine (Phila., Pa. 1976) 32, E176-E180. http://dx.doi.org/10.1097/ 01.brs.0000257565.41856.0f.

Milgrom, C., Radeva-Petrova, D.R., Finestone, A., Nyska, M., Mendelson, S., Benjuya, N., Simkin, A., Burr, D., 2007. The effect of muscle fatigue on in vivo tibial strains. J. Biomech. 40, 845-850. http://dx.doi.org/10.1016/j.jbiomech.2006.03.006.

Nalla, R.K., Kruzic, J.J., Kinney, J.H., Ritchie, R.O., 2004. Effect of aging on the toughness of human cortical bone: evaluation by R-curves. Bone 35, 1240-1246. http://dx.doi. org/10.1016/j.bone.2004.07.016.

Nalla, R.K., Stölken, J.S., Kinney, J.H., Ritchie, R.O., 2005. Fracture in human cortical bone: local fracture criteria and toughening mechanisms. J. Biomech. 38, 1517-1525. http://dx.doi.org/10.1016/j.jbiomech.2004.07.010.

Nalla, R.K., Kruzic, J.J., Kinney, J.H., Balooch, M., Ager, J.W., Ritchie, R.O., 2006. Role of microstructure in the aging-related deterioration of the toughness of human cortical bone. Mater. Sci. Eng. C. 26, 1251-1260. http://dx.doi.org/10.1016/j.msec.2005.08. 021.

Pattin, C.A., Caler, W.E., Carter, D.R., 1996. Cyclic mechanical property degradation during fatigue loading of cortical bone. J. Biomech. 29, 69-79. http://dx.doi.org/10. 1016/0021-9290(94)00156-1.

Piekarski, K., 1970. Fracture of bone. J. Appl. Phys. 41, 215-223. http://dx.doi.org/10. 1063/1.1658323.

Rankine, J.J., Dickson, R. a., 2010. Unilateral spondylolysis and the presence of facet joint tropism (E1111-4). Spine (Phila. Pa. 1976) 35. http://dx.doi.org/10.1097/BRS. 0b013e3181de8b72.

Ritchie, R.O., 1988. Mechanisms of fatigue crack propagation in metals, ceramics and composites: role of crack tip shielding. Mater. Sci. Eng. 103, 15.

Ritchie, R.O., Kinney, J.H., Kruzic, J.J., Nalla, R.K., 2005. A fracture mechanics and mechanistic approach to the failure of cortical bone. Fatigue Fract. Eng. Mater. Struct. 28, 345-371. http://dx.doi.org/10.1111/j.1460-2695.2005.00878.x.

Shah, J.S., Hampson, W.G., Jayson, M.I., 1978. The distribution of surface strain in the cadaveric lumbar spine. J. Bone Jt. Surg. Br. 60-B, 246-251.

Swärd, L., Hellström, M., Jacobsson, B., Peterson, L., 1989. Spondylolysis and the sacrohorizontal angle in athletes. Acta Radiol. 30, 359-364.

Taylor, D., O'Reilly, P., Vallet, L., Lee, T.C., 2003. The fatigue strength of compact bone in torsion. J. Biomech. 36, 1103-1109. http://dx.doi.org/10.1016/S0021-9290(03) 00104-0.

Terai, T., Sairyo, K., Goel, V., Ebraheim, N., Biyani, A., Faizan, A., Sakai, T., Yasui, N., 2009. 87. Stress Fracture as the Beginning of Spondylolysis Occurs from the Ventra Aspect of Pars Interarticularis: a Clinical and Biomechanical Study. Spine J. 9, 46S. http://dx.doi.org/10.1016/j.spinee.2009.08.109.

Toueg, C.-W., Mac-Thiong, J.-M., Grimard, G., Parent, S., Poitras, B., Labelle, H., 2010. Prevalence of spondylolisthesis in a population of gymnasts. Stud. Health Technol. Inform. 132-137.

Winwood, K.L., Zioupos, P., Currey, J.D., Cotton, J.R., Taylor, M., 2006. The importance of the elastic and plastic components of strain in tensile and compressive fatigue of human cortical bone in relation to orthopaedic biomechanics. J. Musculoskelet. Neuron. Interact. 6, 134-141. 